\title{
Balint's syndrome caused by colpocephaly and cerebral infarction
}

Ishida Tetsuro 1, $2^{*}$

${ }^{1}$ Hokujinkai ISHIBASHI Hospital, Nagahashi, Otaru, Japan.

${ }^{2}$ Department of Neuropsychiatry School of Medicine, Sapporo Medical University, Chuo-ku, Sapporo, Japan.

${ }^{*}$ Corresponding author: Ishida Tetsuro. Ishibashi Hospital 3-7-7 - Nagahashi. Zip Code: 047-0036 - Japan. Phone: +81-134-25-6655. E-mail: teturoisida@yahoo.co.jp

Research Ethics Committee Approval (if necessary): We declare that the patient approved the study by signing an informed consent form and the study followed the ethical guidelines established by the Declaration of Helsinki.

Received on: Jul 6, 2021. Accepted on: Jul 12, 2021. Available online: Mon X, 2021.

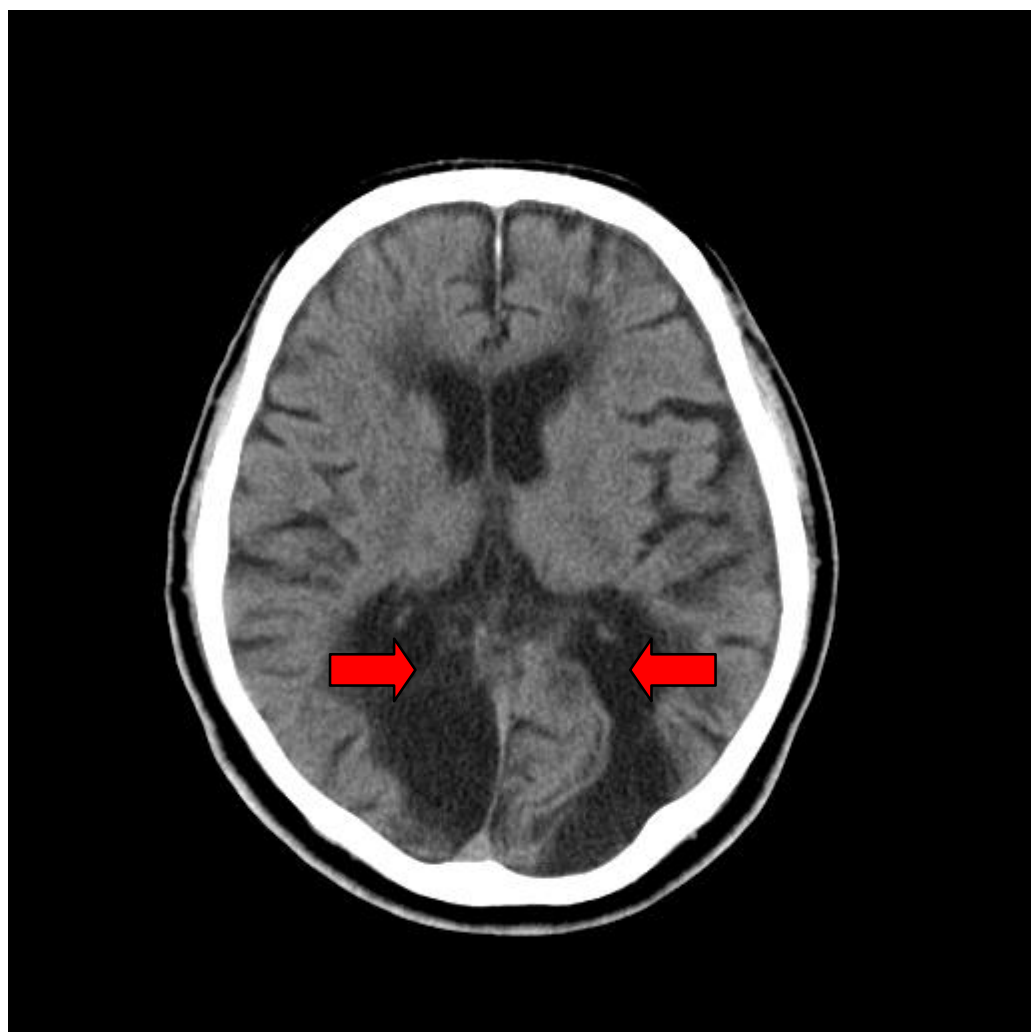

Figure 1. CT exemplify disproportionate enlargement of the occipital horns of the lateral ventricles characteristic of colpocephaly (red arrows).

A 67-year-old man consulted our hospital for "blindness". Since his childhood, he has shown irritation and developmental disabilities. Nine years 
ago, he suffered from cerebellar ataxia. His non-contrast computed tomography (CT) of head showed cerebral infarction and congenital colpocephaly (Figure 1). Physical rehabilitation reduced his wobble. But then he claimed to have impaired vision. Neurological examination showed his simultanagnosia, oculomotor and optic ataxia. He was diagnosed with balint's syndrome, a type of higher brain dysfunction. Rehabilitation based on compensatory strategies gradually improved his quality of life. Now he is living well in the nursing home with the help of staff.

Balint's syndrome is generally due to bilateral dysfunction of the posterior parietal lobe and is rare in cerebral infarction [1]. This case shows that higher brain dysfunction can also occur with infarcts in atypical locations, if there is a congenital malformation such as colpocephaly.

\section{References}

[1] Biotti D, Pisella L, Vighetto A. Syndrome de Balint et fonctions spatiales du lobe pariétal [Balint syndrome and spatial functions of the parietal lobe]. Rev Neurol (Paris). 2012 Oct;168(10):741-53. French. doi: 10.1016/j.neurol.2012.08.003.

Conflict of interest: The author declares no conflicts of interest associated with this manuscript. The patient has provided permission to publish these features including his examination data and imaging findings of his case, and the identity of the patient has been protected.

Acknowledgements: We thank Drs. KAWANISHI Chiaki and UKAI Wataru and MURAYAMA Tomonori and KOBAYASHI Seiju and SHIRASAKA Tomonobu for helpful discussions and comments on the manuscript.

Funding: None.

How to cite this article: Tetsuro I. Balint's syndrome caused by colpocephaly and cerebral infarction. Brazilian Journal of Case Reports. 2021 Jul-Sep; 01(3):12-13. 